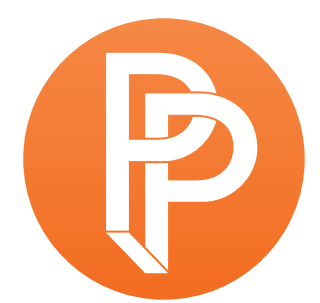

PERFORMANCE

PHILOSOPHY

\title{
'VISIBILITY BRINGS WITH IT RESPONSIBILITY': USING A PRAGMATIC PERFORMANCE APPROACHTO EXPLORE A POLITICAL PHILOSOPHY OF TECHNOLOGY
}

\author{
GERAINT D'ARCY UNIVERSITY OF SOUTH WALES
}

\section{Introduction}

The philosophy of technology is necessarily through its practice, an inter-disciplinary study, with many areas and disciplines contributing to its expansion and exploration, and those same areas borrowing widely from the field to prop up their own disciplines. In 'Has the Philosophy of Technology Arrived?', Don Idhe suggests that there has not been enough of an internal debate within the field of philosophy of technology as a separate discipline from the slightly older philosophy of science, to allow it to 'arrive' (Idhe 2004, 124). Andrew Feenberg considers the field to be 'largely unmapped territory' (Feenberg 1999, 1) which has only recently attracted the attention of the 'currently dominant social theory' which 'seems to have no grasp of the political conditions of its own credibility' (12) and thus lacks social pertinence. If, as Idhe suggests, this debate is as internal as its arrival is immanent, then the identification of a philosophies of technology which are also political and an arena in which to observe them in action would allow that internal debate to take place.

The argument in this area seems currently to be between the "black-box" social constructivists who are too 'socially reflexive' (Winner 1993) and the more Marxist philosophers who are keen to apply the structures of capitalism to the creation of technology (Winner 1993, and Sørenson 2004). The black-box in this case is a technological device or system reduced to its most instrumental function. 
The social constructivists are philosophers of science, such as Bruno Latour or Michel Callon, who shrug off political meaning in their analyses and who effectively support the neo-liberal western hegemony through their refusal to identify specific meaning behind readings of technological developments; pitted against them are those philosophers who side with the left-leaning postphenomenological work of Don Idhe and Langdon Winner, who are concerned with 'the isomorphism of technology and capitalism and the resulting democratic deficit' (Sørenson 2003, 187).

The particular approach that this paper would like to explore is that of productive pragmatism, or instrumentalism, a philosophical approach that aims to experience the use of a technology and discover the relationships associated with its use not merely speculate upon what they might be through thought experiment. This approach offers a philosophical tool for reasoning and considering concepts and issues that are not restricted to reflexive thought experiments or to intellectual reasoning but take place 'as features of a fully fleshed out involvement of the organism within its environment' (Hickman 2001, 47). This approach avoids the issues of essentialism usually levelled at Heidegger and Habermas (Feenberg 1999, 17), which is an approach that reduces a technology to its most basic (or least complex) form and makes observations based on that limited abstraction. Instead, productive pragmatism widens the frame of observation through practical use. Its application in a frame of theatre and performance consequently means applying some of the techniques of social constructivism: a contextualization that avoids a determinist historical approach in order to establish a technology as a semiotic element of performance. As this combination of methods could be considered part of the post-phenomenological approaches to the philosophy of technology, it must refrain from identifying a politics which is exclusively leftleaning and instead identify more widely but positively the political and cultural concepts revealed by such an approach.

This paper hopes to bring instrumentalism to bear upon an example of performance that utilizes technology in an apparently simple way. The performance example used in this paper is small, but it provides access thematically to a number of political questions about power and visibility that can also be applied to the scenographic choices the production made regarding the use of technology in performance. By exploring what implications this could have in terms of a political philosophy of technology, and by expanding the exploration to talk about performance technology and domestic technology more widely, this paper hopes to expand the current discussions of technology both in and outside of a performance frame.

To begin with, this paper will look at the connections between the philosophy of technology and theatre and performance, before moving onto the case study that inspired this exploration, and a discussion of visibility in performance and its relationship to the semiotic significance of performance technologies. The case study is a modest example in itself, but one that serves ultimately as a synecdoche for the final discussion: an exploration of the political relationship between the visibility and usability of technology, and how such a relationship here examined within a performative frame has wider political and social implications. 
As Andrew Bowie has argued, in its way the artificial environment of a theatre or performance can provide a space for organisms to explore 'horizons of sense that can be obscured by dominant cultural forms of attention' (Bowie 2015, 53). Although it could be argued that our society has become thoroughly technologized, the philosophy of technology remains an under-explored area, which this paper aims to contribute to in a small way through an examination of theatre and performance technology by acknowledging the marriage of philosophy and performance as a field of new academic study (Kirkkopelto 2015,4). This would seem to provide an ideal experimental situation 'in order to effect forward-looking adjustment to environing conditions by means of practical effects' (Hickman 2001, 47).

The concept of the black-box in theatre is usually one associated with the black-box studio, a performance space that is supposedly "neutral" because it is painted black and is essentially boxshaped. In the philosophy of technology, a black-box is a metonym used to describe a technological artefact in an empirical social-constructivist analysis described solely in terms of its 'inputs and outputs' (Winner 1993, 365). In theatre and performance, we often have the experience of witnessing, as audience members, interactive black-box artefacts inside black-box rooms, but just as we are supposed to understand that the black-box studio has no significance in the socialconstructivist approach to technology, we are also supposed to think that the technological artefact has no significance beyond the socially-reflexive but often inconclusive readings given to these artefacts by contemporary thinkers and often by theatre scholars. For some philosophers of technology, the concept of the black-box is dissatisfying and the slowly evolving contention in the field hinges upon two arguments: either that a technology can be "read" like a text in multiple ways, but only noting the diversity and flexibility of interpretations; or using those readings to identify a meaning and say why that reading matters (Winner 1993, 373). Not knowing what is inside the black-box has its own thrill in theatre, its own magic, and the theatre utilizes a great many different black-boxes in performance and theatre conceived as a technological artefact, as a black-box itself, relying upon the mystery of what is inside to create meaning or make spectacle, and having done so for some time ( $\left.D^{\prime} A r c y, 2013\right)$. What is often forgotten when discussing technology in theatre is that these are not technologies in domestic or industrial spheres but technologies in a frame that represents those spheres of life. The domestic and the industrial are places of politics, and the theatre is a political form that produces art that is always political even when it is not overtly political in content (Sinfield 1990, 475). When discussed at length by theatre scholars and academics such as Philip Auslander (1999), Steve Dixon (2003), Matthew Causey (2003), Peggy Phelan ([1993] 2001) and Susan Kozel (2004), and by those who discuss the use of media technologies such as Sarah Bay-Cheung et al. (2010), technologies seem to be only ever apolitical black-boxes of inputs and outputs, or at most as texts of multiple indefinite meanings. It would seem that the contentions found in the philosophy of technology have not yet made it to discussions of technology in theatre and performance. This seems a little odd given that the political forms of theatre and performance should provide very fertile ground for exploration into the increasingly contentious construction of a political philosophy of technology. 
Andrew Feenberg and Larry A. Hickman have been technology philosophers at the forefront of discussions that underpin the wider approaches to technology in society, and instrumental in establishing a modern philosophy of technology. What they are seeking in these discussions is a political philosophy of technology, one that can explain the power structures of society as well as the effects 'technology_as our culture' (Hickmann 2001, 4) has upon them. In particular, their work seeks to dismantle the paradox of essentialism, which sees those who try to understand or design technologies and technological systems ultimately 'agreeing implicitly with technocrats that the actual struggles in which people attempt to influence technology can accomplish nothing of importance' (Feenberg 1999, xiv). This creates a situation where as our society becomes more technologized, it also becomes more estranged from both our understanding and our physical being. This paradox of essentialism becomes the main restraint to wresting the power away from the hegemony of late-capitalist governance and giving it to the communities who utilise it (Hickman 2001 , 171). Feenberg in particular thinks that change in the status quo will not come about until 'we recognize the nature of our subordinate position in the technical systems that enrol us' (Feenberg 1999, xiv) and begin to intervene in the design and construction of those systems in a democratic way, and to do so requires an effective political philosophy of technology. Hickman believes the way to achieve this goal is through instrumentalist experimentation reasoned through 'the literary and plastic arts [...] and wherever else systematic, self-conscious, creative, forward-looking adjustment occurs' (Hickman 2001, 47).

Hickman and Feenberg use philosophy as a tool to examine technology as culture in political terms, and this paper would like to offer the political tool of theatre and performance to examine technology in culture. By applying the work of Maurice Merleau-Ponty and Michel Foucault on visibility and power to a reading of a recent adaptation of Jean Genet's The Maids, this paper aims to establish briefly an instrumentalist (Hickman 2001, 44-55) approach to considering theatre technology in performance and technology in culture, and it considers what that approach has to offer to a political philosophy of technology.

Before this paper can continue, though, it needs to establish the dual position of an instrumentalist approach as one that apparently divorces technology from culture, despite the obviousness that it should be a 'seamless part' (Sørenson 2003, 187). The public perception of technology-as-artefact, and one reinforced by the essentialism of the constructivists, is that technology is somehow as separate from culture as it is physically distinguishable from ourselves and therefore apparently also from nature. The irony being that this is because of the methodologies inherent in the essentialist approach, and, in order to be counteracted, this instrumentalism must also work in a similar manner and acknowledge the still deeper irony that nature and culture are artificially separated by such an approach-despite the modern thinking that these things are not separate at all but thoroughly entangled (Braun, 2004). Consequently, essentialist approaches such as the actor-centred methodologies created by Bruno Latour (Kennedy 2010) and utilised by those working in the active public fields of user-centred design (Garrety and Badham 2004) aim to decrease the visibility of this entanglement and deliberately position technology as separate from the user/human. Such an approach is a deliberate "de-politicising" of the technology by artificial means, not least because it artificially separates technology from culture and human/nature from 
culture. It is the eventual aim of this work to show using 'the literary and plastic arts' (Hickman $2015,47)$ that such a "de-politicization" is not at all apolitical but a deliberate obfuscation of the neo-liberal hegemony, and key to this discussion is the concept that relates directly to "what is inside the black-box": namely, to show how to identify the visibility of its entanglements.

\section{Playing 'The Maids'}

At the centre of this exploration is Phillip Zarrilli and Kaite O'Reilly's interpretation of Jean Genet's The Maids (Les Bonnes, 1947), in their 2015 performance Playing 'The Maids' (Kim 2015). This collaborative and intercultural exploration of the themes of Genet's play by the Llanarth Group (Wales), Gaitkrash (Ireland), and Theatre P'yut (Korea), foregrounds the relationship between an omnipresent Madame (Jing Hong Okorn-Kuo) and two sets of servile sisters, played by two Irish actresses (Bernadette Kronin and Regina Crowley) and by two Korean actresses (Jeungsook Yoo and Sunhee Kim). In this examination of Genet's text the international doubling is an extension of Zarrilli's long-running international and cross-cultural theatre practice and of his theatre anthropological research, which, according to the programme notes, 'uses Genet's text as creative inspiration, focussing on its relationships and power dynamics as part of an oblique investigation of modern servitude, wealth-as-privilege, cultural notions of guilt and oppression, phantasms, and the politics of intimacy' (Playing 'The Maids' Programme Notes 2015).

This is a long-term project for Zarrilli in particular as it explores aspects and parts of an old disagreement with the practices of Eugenio Barba about cultural visibility from 1988: 'For whom is the "Invisible" not "visible"? Reflections on Representation in the Work of Eugenio Barba' (Zarrilli 1988). Playing 'The Maids' reflexively incorporates all the explorations they intended, in a balanced multi-lingual and pan-cultural post-modern performance piece, without doing what Zarrilli once accused Barba of doing when he said his work at that time tended to 'mystify the Other and essentialize the performance process' (Zarrilli 1988, 102). In Playing 'The Maids' the collaborative nature of the work produces a text where no one voice or language or performance practice is dominant in its exploration, but instead each practice is made manifest in the work throughout the 'psychophysical scores, choreography, and sound compositions' (Notes 2015); and, as if to directly reference the old argument about cultural visibility, there is a line of dialogue in the performance which seems to echo this argument. At the mid-point of the piece Madame is being dressed to go out and is pampered by both sets of sisters as she gets ready to leave for her function. 'Visibility,' she declares, 'brings with it responsibility.' This is particularly resonant within the play not just because of the academic note it sounds, recalling Zarrilli's earlier contestation of Barba's work, but it also has a particularly French flavour, summoning the work of Genet's contemporary, Maurice Merleau-Ponty and his work The Visible and the Invisible (1948), and also Michel Foucault and the concept of panopticon from Discipline and Punish (1975). Given the subject matter of the original Genet text and the ensemble's intention to make a work that 'interrogates who creates and controls whom' (O'Reilly and Curtin 2015) and that explores 'modern servitude, wealth-as-privilege, cultural notions of guilt and oppression, phantasms, and the politics of intimacy' (Notes 2015), it is likely that this line was included to evoke Foucault's panopticon rather than Merleau-Ponty's dense 
and incomplete philosophical work on the nature of nothingness. A study of the performance in relation to this and the ensemble's international and cross-cultural aims would certainly be interesting, but this paper is focussed on the provocation of thoughts inspired by the scenography of the work and by the inclusion of the sound composition as part of the ensemble's process. A modest example, and one of narrow theatrical significance in the larger field of theatre and performance studies, Playing 'The Maids' is merely a launching point to talk about performance technologies through its thematic access to a discussion about the politics of visibility.

\section{The politics of visibility}

In terms of artistic perception, performance is like a painting, but despite the persistence of the nineteenth-century hangover of pictorial realism in dominating our understanding of visual language in the cinema and (often) on stage, we cannot say our experience of performance is anything like how a painter creates a painting as 'a flat surface of perpetual simultaneity' (Foucault $1973,6)$. Our experience of performance is dynamic, has real depth and surrounds us; however, the function of the gaze, to which Foucault alludes, is comparable. In painting there is represented every detail painted upon a single plane, and to perceive the painting in the way that it was painted with equal attention to each detail is impossible, as our focus shifts and our attention is drawn from one detail to another as we perceive the details over the duration of our gaze. This also happens in performance: everything within the performance frame is part of the scenography and therefore contributes to the semiological sense of the performance-it is all there to be "read" by an audience. Every detail is deliberate, but that is not to say that all of the detail is recognized, understood, or acknowledged by us as we look at it. There is, as Jacques Lacan observes in his lectures 'The line and Light' and 'What is a Picture?', a 'certain dompte-regard, a taming of the gaze, [...]. [H]e who looks is always led by the painting to lay down his gaze' and to look instead at that which the painter wishes them to see (Lacan 1994, 109). The painter for Lacan draws attention and directs the viewer's gaze, and therefore creates meaning in their art by indicating which aspects to look at. The artist can direct the gaze. Foucault's forensic painter, observing and detailing everything in their work, has produced a painting in which everything represented is visible-it can be optically perceived by the viewer, but it may not be objectively perceived or acknowledged by the viewer.

There are therefore two levels of visibility: the optical - that which is physically able to be seen; and the perceptual-that which we look at and acknowledge. These two positions would appear to be separate: one, the optically visible, a physical fact; and the other, the perceptually visible, governed by cultural conditioning. As we gaze at a work of art, painted or performed, these two positions constantly oscillate, and for Maurice Merleau-Ponty they are not separate but constantly intertwined: an object is 'neither thing seen only nor seer only, it is Visibility sometimes wandering sometimes reassembled' (Merleau-Ponty 1968, 139-140)—but always ultimately subjective and relative to the viewer, because as compelling as Lacan's argument is for surrendering what to look at to the artist, it assumes a homogenous and compliant audience who all possess the same cultural knowledge and no independent curiosity. 
It is this extreme point of perception that we can call "invisible": that which is physically present, tangible, and optically visible, but is not perceived by the viewer-or, importantly, is not perceived by the viewer yet. This does not presuppose, however, that such a position will be the same at each moment of a performance, or at an art "viewing" for every viewer, but it does rely on the idea that it can be a possible position for every viewer to experience at a point within the duration of their gaze. It also does not presuppose that a viewer will have their gaze successfully directed by an artist's dompte-regard, their attempt to "tame" the gaze and guide it plaintively to where the artist requires it, but it does suggest that this experience is not out of the question entirely and that this surrender may even be voluntary. If an artist were to persuade a viewer into "seeing" what the artist wanted them to see, with the conventions and cleverness of their painting or performance, that would be politically interesting.

The visibility of a subject in performance has been used since Peggy Phelan and Jill Dolan's work in the 1990s as a 'representational problematic' (Reinelt 1994, 97) to demonstrate in differing ways how a subject/object relationship within a theatrical or performative frame can be a political relationship. Various commentators and critics since that time have reinforced these notions and used them to demonstrate how a body's visibility or invisibility can be a strong political metaphor when the relationship becomes central to the dramatic or performative work. Phelan and Dolan used this theme to effectively analyse gender relationships: for Dolan, it is used to refuse the stability and definition of gender and sex, whilst for Phelan visibility remains a panoptic trap (Reinelt 1994, 98). As Zarrilli's early work and Barba's subsequent response (Barba 1988) to Zarrilli's previously addressed criticism of him indicate, visibility is just as effective in dealing with crosscultural issues as it is with gender issues. As Phelan states in her seminal work Unmarked: 'Performance implicates the real through the presence of living bodies', and as the spectator consumes visually every scrap of the scene presented to them, '[w]ithout a copy, live performance plunges into visibility' due to its ephemerality (Phelan 2001, 148). Phelan assumes that her example performance has been successful in taming the gaze of the entire audience, that they do see everything that is optically evident, and that, being left with only the live body of a woman, they cannot avoid seeing that too: the optically visible here meets the perceptually. With the 'plunge' of a body in live performance into visibility comes the acknowledgement of bodies associated with the performance and those bodies inevitably possess gender, sex and race. Along these lines Phelan makes her argument for the emergence of the female body in performance and the political consequences of being visible. In particular, she picks up on the presence of mediatizing technologies in relation to the body in order to resist the reproduction of metaphor, specifically the metaphor of gender, in order to approach and comment on the 'real' issues of quotidian gender inequality (Phelan 2001, 150).

The oscillation between bodies that plunge into and out of perceptual visibility prove dramatic in their own right as they "appear" and "disappear" on stage for a deliberately and sometimes unavoidable political effect. The politics of the visible and invisible body has become a mainstay of theatrical and performance criticism over the last twenty years, in particular with relation to the body in performance on stage with technologies. The work of Philip Auslander (1999), Susan Kozel (2007), and Mathew Causey (2004) all utilize Phelan's observations to make their own comments 
on the subject matter. With the digital shift gathering pace during the same timeframe, and since the increase in ubiquity of mobile technologies, the borderlands and boundaries between the subject and object and the body and the space have become blurred, extended, or even suspended altogether. Also plunging into visibility has been the material technology, often in the way, interrupting, or obscuring the performance, frequently supporting or extending the action, but always critically, problematically.

\section{Staging 'The Maids'}

'Visibility brings with it responsibility' is a line of dialogue added to Playing 'The Maids' by the ensemble and is not present in the original Genet text. What is resonant with this particular line for this paper is its direct association of something powerful to something that is also perceptually visible. Madame is framed on either side by her four maids as they clamber around on the floor fawning and primping her garments. The tableau is triangular, with Madam at the apex and the maids either side at her feet. Her declaration is a paraphrasing of Foucault's statement regarding the panopticon and the power structures inherent in the object's visibility: 'He who is subjected to a field of visibility, and who knows it, assumes responsibility for the constraints of power' (Foucault 1991 , 202). That subject is optically and perceptually visible and is aware of their visibility to viewers who may not be visible either optically (to the subject) or perceptually (again to the subject). This would have resonance in any normal production of Genet's The Maids, as the 1947 play continually evokes a character who is often not physically present but is made omni-present by the sistermaids' performance of the character in different situations and in repetitions of play-acting games which they perform throughout the course of the play. Madame is not present (optically invisible) but is evoked to be perceptually visible through representation of her character. This was a deliberate attempt by Genet, according to Oreste Pucciani, to invert the 'normal relationship of world and theatre and by a magic of his own turn[s] the theatre into the world' (Pucciani 1963, 44). It would seem that Genet was very much aware of the potential of the stage as a philosophical crucible for political and social experimentation.

In the context of Playing 'The Maids', however, the character of Madame is not merely artificially or theatrically evoked in the space, but is physically present, lurking at the periphery of the black box studio whilst both sets of maids evoke her theatrical presence in their story-telling games. Here Madame is optically visible at almost all times, trailing silk scarves or merely slowly, exactingly moving through and round the space, strolling and reclining in luxuriating positions on the flower festooned stage. Often she is perceptually present to the other characters on the stage, and at times she becomes less perceptually visible for the audience as we lay down our gaze and are directed to view other stage actions through the conventions of the performance, such as when she walks into the darkness and the Maids perform in the light. Her declaration-or rather her acknowledgement-of her own visibility optically, perceptually, and, in terms of the adaptation, theatrically, is particularly interesting considering what other else is visible in the space 'when we mark the smallest signs and natural things that are to be found' (Foucault 1973, 6) in the scenographic frame of the performance. 
The studio space at Chapter Arts Centre, Cardiff, is a small black-box space with end-on audience measuring roughly eight metres to a side of a square playing area. In this space, the ensemble describe two squares, one on the floor with white tape and the other directly above this boundary through the suspension of inverted bunches of flowers. These bunches hang at varying heights above the eye-line of the performers and most of the audience so that they dangle down like drying branches. Within this space are several chairs and two cleaning carts that serve as personal props for the Maids. Upstage-left, hanging amongst the flowers is a white gown on a hanger. At the rear at centre is suspended a video projection screen, and the projector is hidden away in the lighting rig centre-stage. The sole entrance and exit to the space is upstage-right, a doorway leading backstage. Masking that portal and occupying an entire corner of the space is a trestle table covered in sound equipment, consisting of several strange-looking electronic noise makers, Theremins, small keyboards, and mixing desks, as well as a host of decorative props such as a standing porcelain Buddha and several dolls in East-Asian dress. Above this area is a large clock with Roman numerals and hands that do not move. A sound engineer is present (Mick O'Shea). Stage-right of this paraphernalia is a musician (Adrian Curtin) with a cello and a set of microphones and other musical objects. This pair of technician performers are part of the scenography. They are there to welcome us into the space, and they are there when the show finally ends. They never move from this space, nor are they ever plunged into darkness, but instead remain lit throughout the performance. Curtin (listed as a musician, theatre artist and academic in the programme notes) plays the cello, narrates the action and operates small sets of his own equipment or reuses his cello in a percussive or radiophonic way, moving, tapping, and scraping the body to contribute to the soundscape; O'Shea (sound artist) operates a variety of Theremins, keyboards, synthesizers, and sound makers and sound mixers in a similarly diverse and contributively creative way. Their presence is both optically visible and essential to the work.

Despite the variety and technical and creative complexity of their tools, they contribute to the same artistic element: through scoring and punctuating the performance-sometimes cinematically, sometimes radiophonically-they hold together the dramatic tension, play out our genre expectations, and reinforce the fictional world that is evoked. They are performers in that they contribute directly and creatively to the action of the performance, and they are technicians in that they operate a wide variety of technical objects in order to perform this function. Each of those objects have different semiotic meanings, and, depending on how they are used, they are both "black-box technological artefacts" and instruments contributing to the aesthetic of the performance. Their presence is semiotically more significant than that of the video projection and its associated paraphernalia. Their roles in performance are not simply defined as musician and technician as their roles overlap: Curtin would appear to be a musician, holding a cello, but he operates it as a Foley sound artefact at several points, and he takes responsibility for the equipment that controls the levels and tonality of the microphone that he and the Actress playing Madame use. Similarly, O'Shea operates sets of different sound equipment, but consider a synthesizer or a Theremin as "just equipment" at your own peril: they are technologically differently complex to a cello, but no less complex, and no less musical. 
Curtin and O'Shea's core purpose seems to be a bridge between the anti-narrative of the physical performance and the audience's expectations of the source material. Welcoming us into the dimly lit space, Curtin stretches some notes upon his cello while O'Shea mixes soft abstract loops of sound. Into one of several microphones Curtin intones broken half verses of poetry and offers steganographic messages of theatrical welcome ('please remember... all... turn off... thank you'). In his hand is an old dog-eared copy of Genet's text in Faber paperback, presumably covered in notes, from which Curtin reads during the show. He reads sections of stage directions, some real and some extended by the ensemble, and as the action progresses Curtin and O'Shea's verbal and sonic soundscapes shape the mood and the space of the work. After welcoming us and accompanying radiophonically and musically the movement of everything on stage, 'Visibility brings with it responsibility' takes on a particularly interesting flavour. Sound technology is so central to the drama presented, and is perceptually as well as optically visible on stage throughout the performance, as are the two technician-performers and all their technological equipment, taking on a dramatic performative role as well as that of their technical musical one. They are figuratively and literally the cornerstone of the collaboration and the scenography. Madam's truism develops a peculiarly rich harmony with the ideas of Foucault's panopticism: if you can be seen, then you can be responsible. Your visibility can be afforded political weight. If you assume power you also assume punitive responsibility for what is shown: if it goes wrong, it's your fault.

\section{Technology and Visibility}

To begin understanding the import of Madame's statement in relation to the politics of theatre technology beyond Playing 'The Maids', we must first return to Peggy Phelan and one of the central arguments articulating the role or position of technology in live performance from the 1990s. This argument, which has dominated the debate in one way or another for the last twenty years, comes from Philip Auslander and his work Liveness: Performance in a Mediatized Culture (1999), in which Auslander takes specific interest in a case study by Phelan.

In Unmarked: The Politics of Performance (first published 1993) Phelan describes and discusses a work of performance art by the artist Angelika Festa entitled Untitled dance (with fish and others). In this work, the artist is suspended from a pole with her eyes taped shut and her body entirely bound, while a live video feed displays an image of her feet on a screen in the same room as the artist, and an opposing video monitor shows a looped video tape of a fish swimming around. The presence of these mediatized images 'forces the spectator constantly to look away from Festa's suspended body' (Phelan 2001, 156). The spectator is instead invited to consume 'a "blind" image', suggesting that it is 'only through the second-order of a re/presentation that we "see" anything' (Phelan 2001, 156). Phelan provides an accompanying production photograph: to the left of the frame is Festa, her face bound up with scarves and her body apparently suspended by some rig that is out of frame. She is mostly out of photograph's frame, her body obscuring the free-standing projection screen which Phelan described as the "feet-screen", as there is a blurry close-up of her feet on the screen (Phelan 2001, 157). Auslander, in his critique of this work, makes reference to Phelan's observation of this technologically based performance and suggests that her conclusions 
are tautological, finding it interesting that Phelan 'does not specifically address the encroachment of technologies of reproduction' in her analysis of Festa's artwork $(2001,40)$. He goes on to point out that '[i]t is ironic that the video camera, perhaps the sine qua non of the pressures that Phelan sees as compromising the ontological integrity of the performance, is itself integral to the performance in question' (Auslander 1999, 40). Auslander chooses to observe something that is optically visible in Phelan's example but that Phelan has not observed.

Optically visible in Phelan's photograph, but absent in her analysis, are the two objects that Auslander is clearly referring to when he describes the 'encroachment' of technologies: downframe-centre and slightly out of focus is a large RGB projector, and down-frame-right and the most in-focus element of the whole image, a JVC video camera mounted on a tripod. Auslander mentions the camera as being absent in Phelan's analysis, 'the sine qua non' of the encroachment-but he himself neglects to mention the projector and the video monitor with the looped image of the fish swimming. Present in this academic exchange is not two levels of blindness as Phelan suggests, but three: the aversion of the spectators described by Phelan, her omission of anything technological beyond the images viewed, and thirdly Auslander's conflation of the technological system used in the production. Each level of blindness indicates another tier of technological occlusion. Whether these aversions are deliberate or unconscious is interesting because it indicates a lacuna in their production-based critical thinking. These items of technology are responsible for the production of the artwork, and yet Phelan does not see anything but the images they produce. Auslander sees the main technological actant (the video camera) but not the video monitor or the projector. These observations are based on tiers of perception which have governed their visibility and emphasise the subjective cultural differences between Festa, Phelan, and Auslander: Festa presents everything but tries to directs the attention of her audience; Phelan, observes one level of technological visibility in the image the technology produces; Auslander actively looks for another level and observes the encroaching technologies. None of them see each of 'the smallest signs [...] that are to be found' of all of the optically visible technological artefacts (the cables, the tripod, the tape that binds Festa etc.), which detail 'the surface of perpetual simultaneity' (Foucault, 1973. 6). In this case Festa has succeeded in finding her political audience in the tamed gaze of Phelan, but Auslander's subjectivity has affected what he sees in the same performance.

Technology that is seen on stage, as in this instance, is usually the finished product: it is static and unavoidably past, and it is perceptually visible, in the sense that it is no longer perceptually invisible. This is not to say, as Maurice Merleau-Ponty takes pains to point out, that it was not previously non-visible, optically invisible or absent, but that it had been actually present but not perceived (Merleau-Ponty $1968,66,89-98,138-139$ ). If it is seen on stage then it has been perceived to be part of the mise-en-scène of the show; its visual presence in the space must be acknowledged for it to be part of the mise-en-scène, otherwise it is simply ignored or invisible. 'We do not see,' says Merleau-Ponty of the invisible things, 'do not hear the ideas, and even with the mind's eye or with the third ear: and yet they are there, behind the sounds or between them, behind the lights, or between them' (138-139). They are ready to become perceptually visible, not just because they are revealed to us by necessarily physical means to become optically visible-unveiled or un-obscured, 
or in a theatrical sense pushed onto the stage-but simply that they are ready to be perceived when indicated that we should perceive them through the conventions of performance, because the states of perceptual visibility and invisibility are 'the obverse and the reverse of each other' (152). This then is bound up within a performative frame with the semiological significance of the technological: they are black-boxes of inputs and outputs when they are perceptually invisible, but semiologically significant when also perceptually visible. Any technological artefact that is used on stage should have performative semiological significance, but it seems that we are too governed by our everyday conceptualisation of technology as an apolitical, semiotically null black-box, 'where one need understand anything about what goes on inside such black boxes. One simply brackets them as instruments that perform certain valuable functions' (Winner 1993, 365).

In this case, the technology Auslander and Phelan are familiar with can plunge the body into perceptual and political visibility in performance at the sacrifice of its own semiotic visibility. What is offered by Curtin and O'Shea as they guide us through the world of Playing 'The Maids' is very different. They instead present aesthetic questions: What are they there for aesthetically? Are they there to perform or to serve? And that, it would seem, is a political conundrum: are they part of the apolitical black-box of technology or the semiotically "neutral" black-box of the theatre performance? Dominating the upstage-right corner of a small playing space for the entirety of a performance, they are optically and perceptually visible, and they are not allowed to become optically invisible on the stage: they are lit at all times, and even though they may drift out of an audience's gaze at points in the performance-or may even be actively ignored by some members of the audience who are used to ignoring such things-they do not leave the space they occupy and constantly draw attention to themselves dramatically and technically. They cannot become optically, perceptually, or semiotically invisible because they are responsible for the action. The technician-performers and their technologies do not lose their visibility in performance; they are part of the performance, and even if attention can be moved elsewhere (should we allow our gaze to be tamed), they are never entirely invisible.

\section{Technological Aesthetics}

The key to this political and aesthetic conundrum lies with understanding what types of technology we can have on stage, not in terms of product or brand, but in terms of their aesthetic. A social constructivist approach may be suitable to identify and explore ahistorically the creation and use of a technological device or system, but the concept of a black-box described 'solely in terms of its inputs and outputs' (Winner 1993, 365) will not wash scenographically.

Let us take a commonly held assumption that there is technology that is performative and highly visible to an audience and technology that is invisible and in service of the show. Arguments that are less reductive than this assumption are also less pragmatic for our purposes, especially as what we are trying to explore here are common perceptions of technology in quotidian relationships and not a technologist's perception, for reasons that will hopefully become clear. This assumption treats the technology on one level as something which is functional-the magic black box has done something-and on another level, as something of significance-we are witnessing a black box do 
something magical. Everyday technology can be read in a social constructivist manner, but in a frame of performance, the differences and the exchange of positions that a technology undergoes when it is being perceived as technology and when it is not perceived is something that requires careful mapping. For this purpose, two semiotic functions can be proposed as positions that a technology can occupy: specific and psycho-plastic. As with the other distinct positions this paper has been dealing with-visible and invisible, culture and nature-these too are intertwined and entangled and can be viewed subjectively so that they are never quite fixed.

Performative technologies could be referred to as specific theatre technologies, and a theatre technology invented for a special purpose could be said to have a certain specificity. A specific theatre technology, or a technology which has specificity, is a "one trick pony", usually something spectacular designed exclusively for one event or one theatrical effect. It therefore has unique signification within the performative frame it is presented in. A specific technology is singular in its use and in its meaning, and it is used for one aesthetic purpose. An example of a specific theatre technology would be something like the nineteenth-century wood stage device the Corsican Trap, used to facilitate the entrance of a ghost onto stage, or its (spiritual) successor, the Pepper's ghost illusion.

In opposition to specific technologies are technologies that fulfill many roles and that are used to serve the action of the stage. These service technologies are invisible and non-performative, and do not distract from the action of the stage or performance. These service devices can be referred to as psycho-plastic, a term first used in the 1920s by a group of New York artists called the Invisibilists, who hung empty frames in galleries and asked their patrons to fill in the images with their imaginations. Later it was used theatrically by Josef Svoboda to describe his stage designs. These technologies are versatile, adaptable, and have many layers of meaning imposed or read into them by the audience, usually unconsciously. They help complete the illusion of theatre by supporting the scenic action, invisibly maintaining the illusion of the staged action. These are technologies which are not noticed and do not stand out as something specific. These technologies that support the theatrical production arguably maintain the psycho-plastic nature of the performance space. An example would be the digital multiplexing (DMX) protocol technology utilized to control lighting consoles and banks of dimmers, making scenographic lighting remarkably versatile.

It is easy to think of these things as merely one thing or the other: that psycho-plastic only refers to the perceptually invisible service theatre technologies; and that anything specific is only visibly spectacular. If we are in a system of opposition then we are pitting the invisible against the visible; however, these are concepts that do not settle so easily into opposition, as they are both the 'the obverse and the reverse of each other' (Merleau-Ponty 1968, 152). Like invisibility and visibility, they are intertwined, and indeed there are many technologies that could be considered to function aesthetically as both specific and psycho-plastic, and there are some technologies that are partially both, but neither one nor the other, or frequently shifting across different performances and sometimes within a performance. A good example of this is the very problematic and common use of video projection in performance. The projected image-highly visible spectacle, semiotically 
important, and aesthetically specific-is often privileged to the detriment of the projection technologies involved-invisible service technology, semiotically just as important, aesthetically psycho-plastic. Hence the conflicting readings Auslander and Phelan give in the earlier example of Festa's work: Festa's body is aesthetically more important to Phelan; Auslander's gaze is drawn to the technology. Ultimately, theatre technologies can be psycho-plastic and specific at once, the relationship between these two states being fluid and constantly moving, and also relative to what they are being used. Consequently their visibility is dynamic and perspectivally relative to the context used. The Corsican Trap used in a production of Dion Boucicault's The Corsican Brothers, for example, would have been specific, but used in another performance for the entrance of something other than a ghost would find the aesthetic shifting towards a psycho-plastic reading.

The dynamic of this relationship between what becomes visible on stage and what is pushed into invisibility is not things moving "on and "off" stage, being optically revealed or removed, but our attention focussing upon already optically visible and present things. The shift between levels of perception regarding technology in performance also suggests a shift in aesthetics, and can explain the relationships of specific and psycho-plastic technologies not as oppositions but as dynamic, subjectively interchangeable differences. Such a relationship allows us to consider the other beings that our relationship with technology may reveal to us, and can reveal the politics that are manifest within such an interaction.

The instance of Curtin and O'Shea's presence on the stage of Playing 'The Maids' should be psychoplastic: they support the action of the stage as well as adding dramatic texture. If they were positioned in the location hitherto provided for technicians and musicians-for example, off-stage, in a technical box, or half obscured beneath the stage in the orchestra pit-this may well remain the case: their technology could serve to enhance and support the psycho-plastic effect of the production almost exclusively. However, their deliberate scenographic optical visibility gives them not only a dramatic responsibility to the performance, but it binds all their technologies together into one observable/noticeable (perceptually visible) unit and awards them an aesthetic specificity within the performative frame.

\section{Performance Technology in Use}

In The Visible and the Invisible, Merleau-Ponty extends his philosophy of vision into the sense of touch, which is important to this discussion because that which is tangible 'is not a nothingness of visibility, it is not without visual existence' (Merleau-Ponty 1968, 134). There can therefore be a situation where a viewer can be in direct physical contact with an object, but still not acknowledge that contact and not acknowledge that the object is in physical terms "visible" or "tangible". Tangibility is not really an applicable extension to use, as the implication of an optically visible object is that it can-be-touched; rather, in technological terms the question that it provokes is "can it be used?" This question raises other questions: is it being applied correctly? is it broken? do I know how to use it? Essentially they key question becomes: what is its usability? The context of the answer will provide the detail, but the answer must occupy a point between usable or unusable depending on the function. If an audience member was to stroll across the stage and pick up 
Curtin's cello, for instance, they would be able to "use" it at a base tangible level-strum it to make a sound-or they may be virtuosic and be able to use it to a high degree. Either way, with imagination, that instrument can have a number of uses beyond its intended function as a musical instrument: it could be wielded as a weapon, or used as a paperweight or doorstop, or, as Curtin does in the performance, turned into a Foley sound effect. If they broke it, they would not be able to use it as a cello instrumentally (in technological terms not just musical); it would be broken and less usable. If they still used it as a weapon or as a paperweight, however, the function would obviously be different, and so the usability would also be different. In the context of the performance in which Curtin used the instrument as a cello, a Foley effect, and a percussive instrument, it had multiple uses but an alterable aesthetic function, becoming more psycho-plastic, or becoming more specific as the action shifted.

In performance it is not usual for an audience member to have direct contact with technological elements of the performance. We can have no experience of using the technologies that Curtin and O'Shea do within the contexts of the performance, and therefore we have no domestic access to the technologies. They are not usable to us as audience; however, in this instance they are perceptually visible. The performance frame makes obvious to us a set of relationships between user and technology by affording them textual significance within a theatrical frame. To the audience, the cello is unusable, as it is unreachable, but we can perceive it in use when our attention is directed at it. From Curtin's perspective the visibility of the instrument would be different: virtuosity in using an instrument is a movement towards an embodied knowledge, and therefore to a reduced perceptual visibility, but a shift in the function in which one uses the instrument in a different way is irregular, less embodied, more visible. The issue of the embodiment of technology, or of technology extending the body, and its relationship to perceptual visibility and a technology's usability is one that requires further unpicking.

\section{Embodiment and visibility}

Theatrical space has always been inextricably technological, as theatre is cultural and the two are 'seamless' (Sørenson 2003, 187), so it is strange that the technologization of theatre seems only evident now. Perhaps it is because technology in society has become more perceptually visible to the public that theatre technologies have also become more visible and have found themselves a more central position in theatre and performance studies. Digital technology and new media technologies allow us to stage the urbanity of our lives (Birringer 1998, 258-353; Giannachi, 2007; Jensen 2007 61-66), allowing us to heighten and publicize our lives in ways previously only familiar in a theatrical frame. According to Erving Goffman, in an everyday strip of life there are many social frames (Goffman 1986, 561), and according to Erika Fischer-Lichte one of those everyday frames is theatrical because technology allows us to theatricalise what is "everyday" and not just our performances:

The simulacrum has become 'experience' [...], and appearance in the media [...] turns out to be one in which reality-traditionally experienced and defined in opposition to appearance-has dissolved entirely. Thus the new media contribute 
The modern theatre space is therefore a visibly technologized one because the fringes of the frame bleed across one another and the everyday is visibly technologized. We find our bodies extended by technologies in the performance space. For Susan Kozel, technology and the human body have to be interchangeable in performance; they reveal each other, and their relationship has the 'dynamic, shifting ever-changing quality of what makes us who we are' (Kozel 2007, 76). It is 'not out of the question for technologies to reveal aspects of embodiment' (75), becoming an extension of our being. Kozel suggests that working with technology in performance reveals deeper aspects to a performer: 'layers of physical, conceptual and social knowledge that are revealed through digital/physical interfaces' (75), layers that are only uncovered by using technology in performance. Merleau-Ponty argues that when observing things in relation to ourselves 'there is an overlapping or encroachment, so that we must say that the things pass into us as well as we into the things' (Merleau-Ponty 1968, 123). He is careful to point out, however, that this is an encroachment and not a blending of our bodies with that which we observe, 'for then the vision would vanish at the moment of formation, by disappearance of the seer or of the visible' (131). So a movement towards embodiment is a movement towards further invisibility up to the impossible limit of vanishing altogether. When a musician is virtuoso, or a programmer is expert, or for anyone who drives a daily commute, their use of an associated technological device becomes to a large extent embodied. The perceptual visibility of those devices decreases and moves towards the perceptually invisible. They are not thought of as perceptually separate to us; they are only used. There is a correlation between a technology's functional usability and its perceptual visibility as a technology. The use of technology in performance frames this correlation.

The use of psycho-plastic technologies to support performative action through means of the audience's imagination could be said to be embodied, with parts of the theatre as a machine or arguably extensions of the theatre's body, so that outside a performative frame, in the everyday, it would be more properly considered that these technologies are potentially embodied extensions of one's being. The corollary may therefore follow that as everyday technologies become extensions of our being-the ubiquitous mobile phone, for example-because they are unable to become actually part of our being, they must vanish to our perception. A further relationship this paper suggests, therefore, is that there is a correlation between a technology's usability and its visibility to the effect that a technology that can be used in so easy a manner that it becomes an embodied extension of ourselves will lose its visibility to us as a technology. Functionally they may no longer be aesthetic objects in the everyday, but they can still be "read" as texts. They may retain their functional plasticity, but in this paper's argument, beyond advocating for its use in theatre and performance, the 'psycho' prefix, is one that should remain in the performative frame; while perhaps plastic is an adequate quotidian and pragmatic partner term for specific to be used when applying these relationships to examples in the everyday. 
Andrew Feenberg observes that technology seems to affect democratic processes, but the development of technology seems to have little democratic input beyond those associated with capitalist processes. He argues that 'since technology embraces more and more social life, these struggles promise to become more frequent and more significant. Can we rest content with a philosophy of technology that is unable to comprehend them?' (Feenberg 1999, xiv). This paper has outlined some relationships that are framed by performance and made evident through their significance in reading them. It has so far avoided left-leaning conclusions, but if we centre the action of performance upon these relationships, or if we make these relationships an integral part of the action, then performance is well-placed to examine the struggles to which Feenberg refers. Performance can provide the arena for the philosophy of technology to carry out its internal debates and explore the manifestations of theory and the 'enormously diverse kinds of technology in the world' (Winner 1993, 363), and it can allow the field to explore its speculations in less abstract forms so that they will not be considered 'vacuous and arm-chair bound' by the opposing school's 'rich empirical detail of social science studies of technology' (Winner 1993, 364). To do this, however, leaning-left politically seems to be a very obvious direction to take. As a conclusion to the case study of Playing 'The Maids', what follows is a political reading of what is implied by the presence of Curtin and O'Shea, and by inference the inclusion of technology and those who use it within a performative frame.

As Merleau-Ponty points out, our being through the act of seeing 'is seen' (Merleau-Ponty 1968, 99): our body looking is 'my body looked at' (123) because we never see from a position of nothingness, so the technological object that that is viewed by a being is only 'a double' of one viewed by another in their own 'camera obscura' (122). The average theatre-goer is unused to seeing the protagonists of backstage. These are people who are deliberately hidden to preserve the "magic" of the theatre experience and the integrity of the illusion, so they are invisible people; but we know what they look like because we know what the theatre looks like when the illusion fails and "backstage" enters. O'Shea and Curtin are visible technicians, and their responsibility reminds us of other technicians we might see. However, it is rare to see a technician on stage, as many years of convention has ensured that this is "not done". We even dress them in black so that if they are "onstage" they are optically less visible, in the hope that they are also perceptually less visible. The technician-performers represent, by proxy, the technology's failure, and they also represent other technicians and technologists in our relationships with our technology, for each technological object holds within itself the aesthetic of its own potential failure: the cracked screen of the smartphone, the "blue screen of death" of the PC, the "beachball of death" of the iMac, static on analogue televisions, digital tearing and judder on digital televisions, the infinite buffering circle of any streaming video. A technology's failure pushes that technology into perceptual visibility, and with it we are made aware that there are other people with other perspectives of the same technology when our technology fails. We rarely think of mechanics when driving, unless the service is due, or we hear a new noise; taking our new phone back to the "genius" who sold it to us is the last thing on our minds when we open its box; we do not spare a thought for the washing machine repairperson as we put on a load, only when the machine will not work. At the point of a 
technology's failure we become especially aware of it, it becomes visible to us, and what also becomes visible is the technician who views that technology in an entirely different way to us. This is not to say that the technician does not experience the same phenomena with technologies themselves. It is unlikely that all technologies are perceptually visible to them: they may be adept at mending a machine, but when their tool for doing so breaks, it too will become visible and with it the being who can fix it. In the frame of the performance O'Shea and Curtin remind us of the technician, as do the performers who operate the televisions and cameras and other specific theatre technologies used by The Wooster Group, Blast Theory, or Kneehigh, for example. In reminding us of the invisible technician, we are reminded of the failure of the technology, not because it is failing, but because they are operating it inside a performance frame to which we do not have access. So, as we gaze at the performance, the technology becomes visible and they, as now visible technicians, are responsible for it.

As our everyday technologies fail they become visible to us, and with these failing technologies come technicians. Their bodies are pushed into visibility. With their emergence into our gaze this visibility becomes political because 'visibility is a trap' (Foucault 1991, 200). In the current neo-liberal climate of late capitalism, the technician is an underclass, offering a service each time they become visible to the user to fix or assist in the unusable technology. The technician and the user in this circumstance can "see" the technology, but when the technology is fixed, the technology for the user falls back into invisibility, and with it the technician. The assumption for the technician must be that because the technology is visible to them, they must also be visible to the user: for them the technology is both visible and embodied. Consequently, they assume they are 'perfectly individualized and constantly visible' (Foucault 1991, 200), but of course they are 'the object of information, never a subject in communication', and consequently their consciousness of permanent visibility in that relationship 'assumes the automatic functioning of power' (201). The user only sees them when the technology is unusable, when it is visible and the technician is responsible. When it becomes embodied again, the user no longer sees the technician, and they become invisible once more. Playing 'The Maids' explores power dynamics and modern servitude as its theme, and its scenography highlights those same relationships by making the use of technology visible.

In anticipating "the next technological revolution" Larry A. Hickman visits Heidegger's early 'brilliant analysis of the deep fissure that divides two types of technological response to the world' (Hickman 2001, 173). On one side there are technologies we have 'assimilated to our quotidian lives' that have made them 'virtually transparent in use', whilst on the other side there technologies which require 'conscious instrumental engagement' (Hickman 2001, 178). In short: some technologies are invisible to us, and that is philosophically problematic as it suggests a political relationship as well as a physical one. Hickman points out that Heidegger's work and the works of Merleau-Ponty advanced our 'understanding of human situatedness and embodiment', but were unable to offer a 'reform of technical culture' (178) with a view to describing how a political philosophy of technology might be formed. In attempting the same project, Feenberg acknowledges: 
Real change will not come when we turn away from technology toward meaning, but when we recognize the nature of our subordinate position in the technical systems that enrol us, and begin to intervene in the design process in the defense of the conditions of a meaningful life and a liveable environment. (Feenberg 1999, xiv)

A more dangerous implication than this paper has heretofore raised, especially when considering the ubiquity of mobile communications technology, is that it may be not only the technician who is invisible, but the technologists who govern the technologies, or the governments who wish to control the technologies or use it for observation of the people. If we acknowledge their existence as beings who are unverifiable, the user and the technician will never know if they are 'being looked at at any one moment; but must be sure that' they must '...always be so' (Foucault 1999, 201). But this is just one political reading of a modest example and is perhaps for another wider discussion and another paper. For now this paper offers a view of what theatre can offer to the field of the philosophy of technology. For Genet, 'in the theatre everything happens in the visible world and nowhere else' (Pucciani 1966, 48), and the theatre can explore many worlds; but each time it brings technology to the centre of attention it is making a political statement, for that technology is visible and with it comes responsibility.

\section{Works Cited}

Auslander, Philip. 1999. Liveness: Performance in a Mediatized Culture. London: Routledge.

Barba, Eugenio. and Phillip Zarrilli. 1988. 'Eugenio Barba to Phillip Zarrilli: About the Visible and the Invisible in the Theatre and about ISTA in particular.' Theatre Drama Review 32 (3): 7-16. https://doi.org/10.2307/1145900

Bay-Cheng, Sarah, Chiel Kattenbelt, Andy Lavender, and Robin Nelson, eds. 2010. Mapping Intermediality in Performance. Amsterdam: Amsterdam University Press.

Birringer, Johannes. 1998. Media \& Performance: Along the Border. Baltimore: Johns Hopkins University Press.

Bowie, Andrew. 2015. "The 'Philosophy of Performance' and the 'Performance of Philosophy'." Performance Philosophy 1: 51-58. https://doi.org/10.21476/PP.2015.1131

Braun, Bruce. 2004. 'Nature and Culture: On the Career of a False Problem.' In A Companion to Cultural Geography, edited by James S. Duncan, Nuala C. Johnson and Richard H. Schein, 151-179. London: Blackwell. https://doi.org/10.1002/9780470996515.ch11

D'Arcy, Geraint. 2013. 'The Yellow Sound an unstageable composition? Technology, modernism and spaces that should-not-be.' Body, Space, Technology 12.

http://people.brunel.ac.uk/bst/vol12/geraintdarcy/geraintdarcy.pdf

Causey, Matthew. 2004. Theatre and Performance in Digital Culture: From Simulation to Embeddedness. London: Routledge.

Dixon, Steve. 2009. Digital performance. Cambridge, MA: MIT Press

Fischer-Lichte, Erika. 1997. The Show and the Gaze of Theatre: A European Perspective. Iowa City: University of Iowa Press. 
Feenberg, Andrew. 1999. Questioning Technology. London: Routledge.

Foucault, Michel. 1973. The Birth of the Clinic: An Archaeology of Medical Perception Translated by Alan Sheridan. London: Taylor and Francis.

___. 1991. Discipline and Punish: The Birth of the Prison. Translated by Alan Sheridan. London: Penguin.

Garrety, Karin and Richard Badham. 2004. 'User-Centred Design and the Normative Poltitics of Technology.' Science, Technology, \& Human Interventions 29 (2): 191-212.

Giannachi, Gabriella. 2004. Virtual Theatres: An Introduction. London: Routledge.

Goffman, Erving. 1986. Frame Analysis: An Essay on the Organization of Experience. New York: Harper and Row.

Hickmann, Larry A. 2001. Philosophical Tools for a Technological Culture: Putting Pragmatism to Work. Bloomington: Indiana University Press.

Idhe, Don. 2004. 'Has the Philosophy of Technology Arrived? A State-of-the-Art Review.' Philosophy of Science 71 (1): 117-131. https://doi.org/10.1086/381417

Jensen, Amy Petersen. 2007. Theatre in a Media Culture: Production, Performance and Perception Since 1970. Jefferson: McFarland \& Co.

Kim, Sunhee. 2015. 'Playing the Maids public promo.' https://www.youtube.com/watch?v=stWcbtqN6kQ

Kirkkipelto, Esa. 2015. "For what do we need Performance Philosophy?" Performance Philosophy 1: 4-6. https://doi.org/10.21476/PP.2015.117

Kozel, Susan. 2007. Closer: Performance, Technologies, Phenomenology. Cambridge, MA: MIT Press.

Lacan, Jacques. 1994. The Four Fundamental Concepts of Pyscho-analysis. Translated by Alan Sheridan. London: Penguin.

Llanarth Group, Gaitkrash, and Theatre P'yut. 2015. Playing 'the Maids'. Programme Notes. Cardiff: Chapter Arts Centre.

Merleau-Ponty, Maurice. 1968. The Visible and the Invisible. Translated by Alphonso Lingis. Evanston: Northwestern University Press.

O'Reilly, Kaite and Adrian Curtin. 2015. 'Intercultural Dramaturgy.' Exeunt, February 17. Accessed June 29, 2015. http://exeuntmagazine.com/features/playing-the-maids-intercultural-dramaturgy/

Phelan, Peggy. (1993) 2001. Unmarked: The Politics of Performance. London: Routledge.

Pucciani, Oreste F. 1963. 'Tragedy, Genet and The Maids.' The Tulane Review 7 (3): 42-59. https://doi.org/10.2307/1125083

Reinelt, Janelle. 1994. 'Staging the Invisible: The Crisis of Visibility in Theatrical Tepresentation.' Text and Performance Quarterly 14 (2): 97-107. https://doi.org/10.1080/10462939409366075

Sinfield, Alan. 1990. 'Theatre and Politics.' In Encyclopedia of Literature and Criticism, edited by Martin Coyle, Peter Garside, Malcolm Kelsall, and John Peck, 475-487. London: Routledge.

Sørenson, K. H. 2004. 'Cultural Politics of Technology: Combining Critical and Constructive Interventions?' Science, Technology, \& Human Interventions 29 (2): 184-190.

Winner, Langdon. 1993. 'Upon Opening the Black Box and Finding it Empty: Social Constructivism and the Philosophy of Technology.' Science, Technology, \& Human Values 18.3: 362-378. https://doi.org/10.1177/016224399301800306

Zarrilli, Phillip. 1988. 'For Whom is the "Invisible" Not Visible?: Reflections on Representation in the work of Eugenio Barba.' Theatre Drama Review 32 (1): 95-106. https://doi.org/10.2307/1145872 


\section{Biography}

Geraint D'Arcy is a lecturer in theatre and drama at the University of South Wales. He has published papers on aspects of the manifestation of technology and information in popular culture and upon theatre technology and scenography. His 2011 PhD was entitled Towards an Aesthetics of Theatre Technology. Geraint is currently writing a book on film and television set design.

(c) 2017 Geraint D'Arcy

(c) (i) (2) Except where otherwise noted, this work is licensed under a Creative Commons Attribution-

cc) NonCommercial-ShareAlike 4.0 International License. 